\title{
Finite element modeling for the progressive collapse analysis of steel stiffened-plate structures in fires
}

\author{
Min Gyu Ryu ${ }^{\mathrm{a}}$, Kunhou He ${ }^{\mathrm{b}}$, Dong Hun Lee ${ }^{\mathrm{a}}$, Sung-In Park ${ }^{\mathrm{a}, \mathrm{d}}$, Giles Thomas ${ }^{\mathrm{b}}$ and \\ Jeom Kee Paik ${ }^{a, b, c^{*}}$ \\ ${ }^{\mathrm{a} D e p a r t m e n t}$ of Naval Architecture and Ocean Engineering, Pusan National \\ University, Busan, Republic of Korea \\ ${ }^{b}$ Department of Mechanical Engineering, University College London, London, UK \\ ${ }^{c}$ The Korea Ship and Offshore Reseach Institute (The Lloyd's Register Foundation \\ Research Centre of Excellence), Pusan National University, Busan, Republic of Korea \\ ${ }^{\mathrm{d}}$ Korea ship building \& Offshore Engineering, Seoul, Republic of Korea \\ *Corresponding author. j.paik@ucl.ac.uk
}

\begin{abstract}
This paper is a sequel to the authors' articles which provided the test data on the progressive collapse of full-scale steel stiffened-plate structures without and with passive fire protection (PFP) under lateral patch loading in fires [1,2]. The present paper presents new computational models for the analyses of heat transfer and fire-induced progressive collapse behaviour of steel stiffened plate structures without or with PFP. For this purpose, transient thermal elastic-plastic large-deformation finite element models were formulated. The developed computational models were validated by a comparison with the test data. The novelty of the paper is associated with a new procedure for the fire-induced progressive collapse analysis of steel stiffened-plate structures which may be a contribution to fire safety engineering of steel plated structures.
\end{abstract}

Keywords: Steel stiffened-plate structure, fire safety engineering, fire-induced progressive collapse, heat transfer analysis, transient thermal elastic-plastic large-deformation analysis, passive fire protection

\section{Introduction}

Steel stiffened-plate panels are used in naval, offshore, mechanical and civil engineering structures as primary strength structures. They are rarely subjected to fire accidents, which may result in structural collapse leading to casualty or severe damages to asset and the environment.

Fire safety engineering is a key design consideration for structures on land and at sea $[3,4]$. In ships and offshore structures, hydrocarbon fires usually stem from oil and gas leaks with ignition [4-12]. The authors contributed to the fire-induced progressive collapse testing of full-scale steel stiffened-plate structures under lateral patch loading $[1,2]$. Many useful studies are found in the literature in association with the fire-induced progressive collapse analysis of land-based structures which are rather 
portal frames than plated structures [13-30]. Lou et al. [13] performed fire tests on full-scale steel portal frames associated with progressive collapse. Passive fire protection (PFP) is recognised as an effective option to protect structures in fires [4, 31-40,48,49]. Fire safety engineering requires quantification of how much PFP contributes to delaying the structural collapse so that a greater period of time can be attained in the process of escape and evacuation.

In the earlier articles [1,2], the authors obtained the test data on the progressive collapse of full-scale steel stiffened plate structures without or with PFP under lateral patch loading in fires. The present paper is a sequel to these earlier articles. In this paper, computational models were developed using transient thermal elastic-plastic large-deformation finite element method. The computational model to analyse heat transfer from ambient temperature to steel temperature was developed for steel plated structures without or with PFP. The computational model for the analysis of the fire-induced progressive collapse behaviour without or with PFP was formulated at the elevated temperature. The computational models were validated by a comparison with the test data.

\section{Computational models}

The procedure for the quantitative fire risk assessment and management of structures and infrastructures [4] requires the fire-induced progressive collapse analysis [41] for identifying the fire consequences. Key tasks to analyse the fire-induced progressive collapse behaviour are: heat transfer analysis to define temperature in steel transferred from ambient temperature elevated due to fire, and thermal elastic-plastic large-deformation analysis to identify the progressive collapse behaviour.

Two methods are relevant to calculate the steel temperature from gas temperature, namely thermal analysis method and heat transfer equation method. Heat transfer equations for structures without or with PFP in fire may be obtained from EN 1993-1-2 [42]. Thermal analysis for steel structures without PFP can be conducted by finite element method using plate-shell elements [41]. PFP is usually modelled using solid elements as described by Paik [4], but for computational costs, a single layer 'shell' element may also be employed. In the present study, the developed models were implemented into LS-DYNA code [43] for the thermal analysis for steel plated structures without or with PFP.The PART_COMPOSITE function in LS-DYNA code was employed to model steel and PFP using shell elements in a 'single layer'. The temperatures of lower, middle and upper surfaces of the shell can be different and they were calculated separately considering the shell thickness. This was possible in LS-DYNA code even if steel and PFP were modelled using single layer shell elements. 


\subsection{Heat transfer analysis}

For the heat transfer analysis, the heat fluxes transferred from the fire to surrounding structures with time must be defined. The total heat flux per unit area $q_{\text {total }}$ is calculated by the sum of the contribution to heat flux by convection $\left(q_{c}\right)$ per unit area and heat flux by radiation $\left(q_{r}\right)$ per unit area:

The heat transfer by convection between the structural element with the temperature $\theta_{m}$ and the surrounding gas cloud with the temperature $\theta_{g}$ is suggested by Cengel and Ghajar [44].To define the coefficient of convection $\left(h_{c}, \mathrm{~W} / \mathrm{m}^{2} \mathrm{~K}\right)$ an engineering judgement can be attempted. Table 1 indicates typical values of the convection heat transfer coefficient [45].

The heat transfer by radiation between the structural element at absolute temperature $\theta_{m}$ and fire environment at an absolute temperature $\theta_{g}$ is suggested by Franssen and Real [45].

Table 2 indicates radiation emissivity coefficients for different metals, following Cengel and Ghajar [44].

The BOUNDARY_FLUX SET function in LS-DYNA code allows the user to input convection and radiation coefficients corresponding to each structural member. In addition, if different sides of the member exposed to a different temperature, different conditions can be entered on the lower and upper surface of the shell.

Table 1. Typical values of the convection heat transfer coefficient $h_{c}$ [45].

\begin{tabular}{|l|l|}
\hline Parameter & $h_{c}\left(\mathrm{~W} / \mathrm{m}^{2} \mathrm{~K}\right)$ \\
\hline Unexposed side of separating elements: & \\
Radiation considered separately & 4 \\
Radiation implicitly considered in the convection & 9 \\
\hline Surface exposed to the fire: & \\
Standard fire curve (ISO 834) & 25 \\
Hydrocarbon fire curve (EN 1991-1-2) & 50 \\
Parametric fire, zone fire model, or external member & 35 \\
\hline
\end{tabular}

Table 2. Radiation emissivity coefficient $\varepsilon_{s}$ for different metals [44].

\begin{tabular}{|l|l|l|}
\hline \multicolumn{1}{|c|}{ Material } & \multicolumn{1}{|c|}{ Surface type } & \multicolumn{1}{c|}{ Emissivity $\left(\varepsilon_{s}\right)$} \\
\hline \multirow{3}{*}{ Steel } & Polished sheet & $0.08-0.14$ \\
& Commercial sheet & $0.20-0.32$ \\
& Heavily oxidized & 0.81 \\
\hline
\end{tabular}




\begin{tabular}{|l|l|l|}
\hline \multirow{5}{*}{ Stainless steel } & Polished & $0.17-0.30$ \\
& Lightly oxidized & $0.30-0.40$ \\
& Highly oxidized & $0.70-0.80$ \\
\hline \multirow{4}{*}{ Aluminum alloy } & Polished & $0.04-0.06$ \\
& Commercial sheet & 0.09 \\
& Heavily oxidized & $0.20-0.33$ \\
& Anodized & 0.80 \\
\hline
\end{tabular}

\subsection{Nonlinear structural analysis}

For the nonlinear structural response analysis, the definition of adequate boundary conditions and design loads of the target structure is required. The BOUNDARY_SPC_SET function in LS-DYNA allows the user to input the translational constraint and rotational constraint of nodes. To apply the load condition, the LOAD_NODE_SET function can be used for external loads and the LOAD_BODY_Z function can be used for the application of the gravity. Besides, using the CONTACT function, various contact conditions can be entered. It is very important to accurately define the mechanical and thermal properties of the material to perform a highly reliable heat transfer and structural response analysis.

Modelling of steel structures using shell elements and modelling of the PFP using solid elements is time-consuming. As such, simplified models were considered in the present study, where the PFP was modelled as a virtual steel plate with a single layer. The accuracy of this simplified model using shell elements was verified with an example on steel plate with gypsum board PFP. Figure 1 shows the finite element model using shell elements for steel and solid elements for PFP. Figure 2 shows the finite element model using shell elements for both steel and PFP.

The number of nodes and elements using solid elements was 20,402 and 20,000 respectively, and the number of nodes and elements using shell elements was 10,201 and 10,000, respectively. The shell element model is useful in terms of reducing the modelling process and computational cost [47].
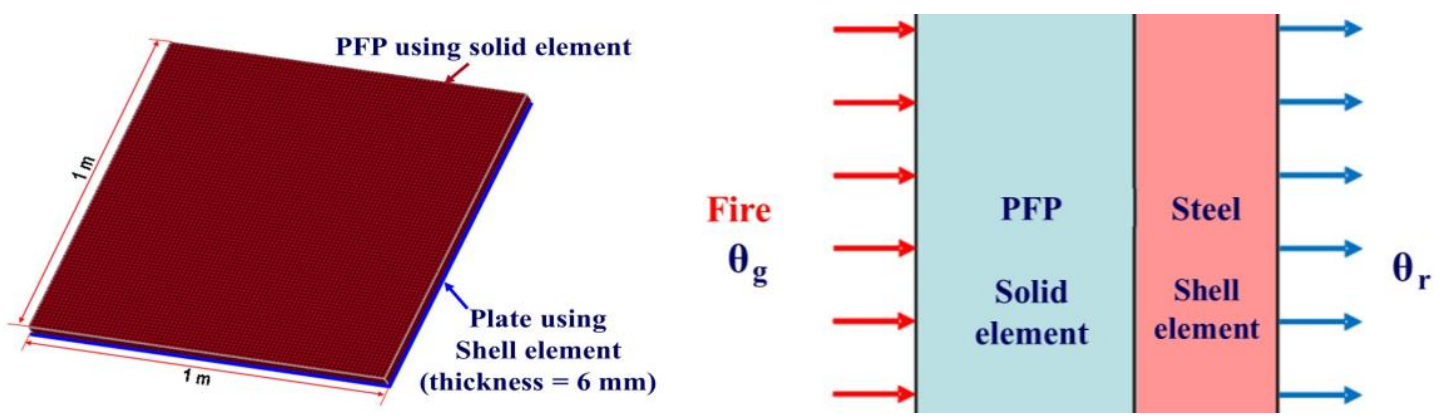

Figure 1. Finite element model using shell elements for steel and solid elements for PFP. 

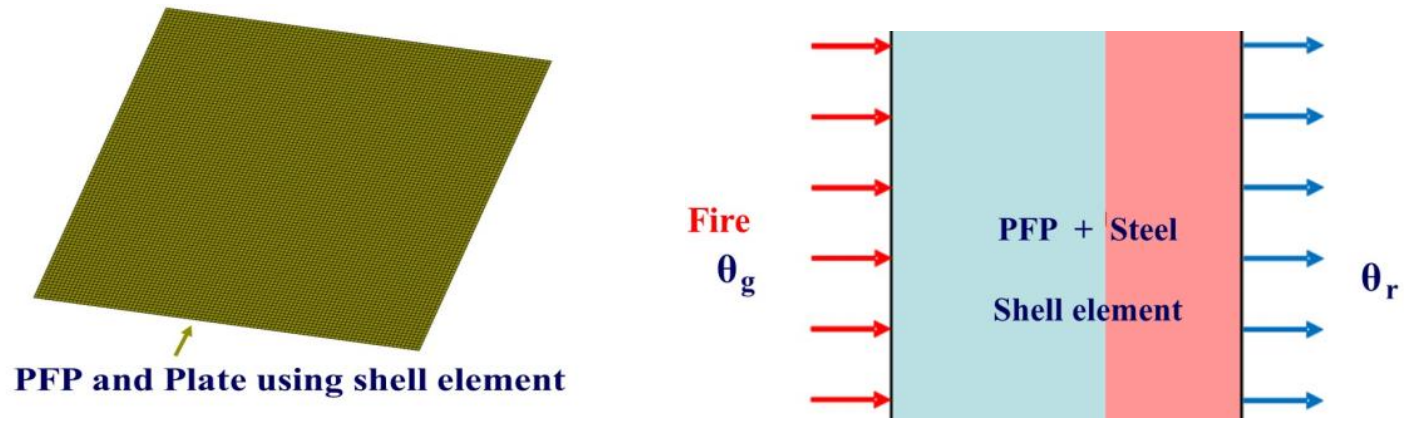

Figure 2. Finite element model using shell elements for both steel and PFP.

For the heat transfer analysis of steel structure with PFP, thermal properties of steel and PFP must be defined. The specific heat and conductivity of steel vary with temperature, as shown in Figure 3. The thermal properties of gypsum board PFP, such as its temperature-dependent thermal conductivity and specific heat are presented in Figure 4 [46]. The bottom side of the steel plate with the gypsum board was subjected to the gas cloud temperature. It was assumed that the gas cloud temperature distribution is uniform. Heat loss on the unexposed side was considered with heat flux due to convection and radiation. The thermal load was applied following the profile, as shown in Figure 5. The steel temperature was not exactly the same as the gas cloud temperatures because of radiation and convection. Therefore, the heat transfer analysis was performed with the coefficients associated with the convection and radiation, which was taken as $10 \mathrm{~W} / \mathrm{m}^{2} \mathrm{~K}$ for convection and 0.8 for the effective surface emissivity of the gypsum board. It was assumed that the ambient room temperature was kept constant because of the large room volume and sufficient ventilation.

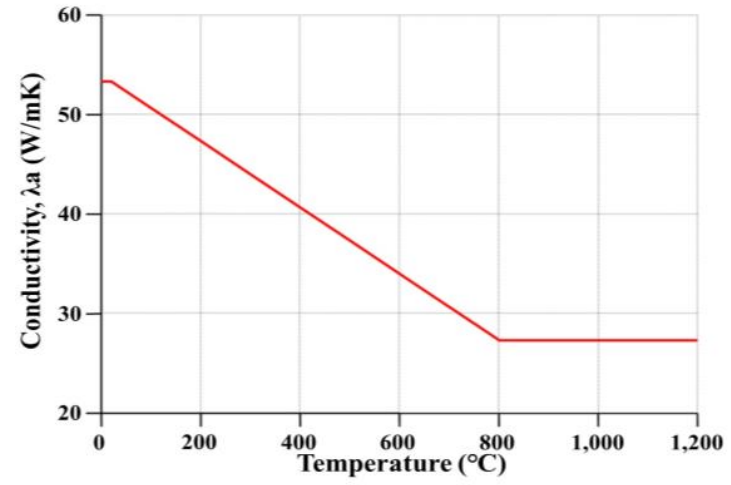

(a) Thermal conductivity of carbon steel

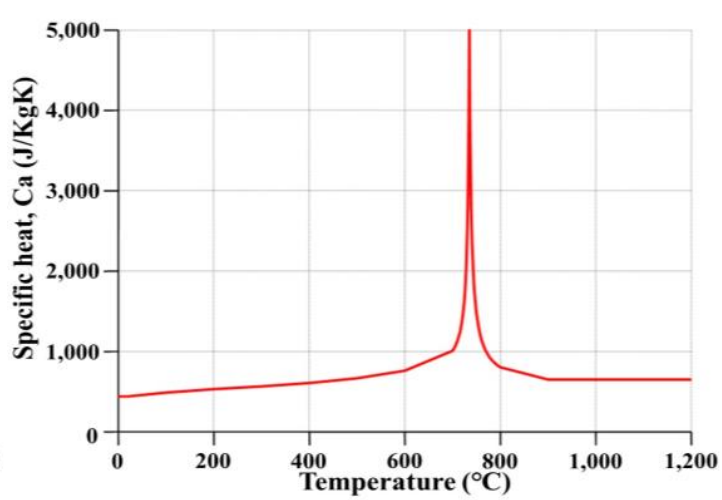

(b) Specific heat of carbon steel

Figure 3. Thermal properties of carbon steel. 


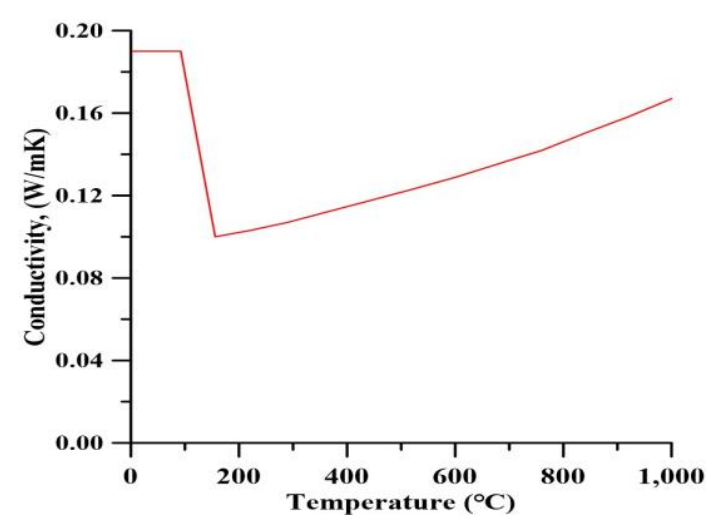

(a) Thermal conductivity of gypsum board

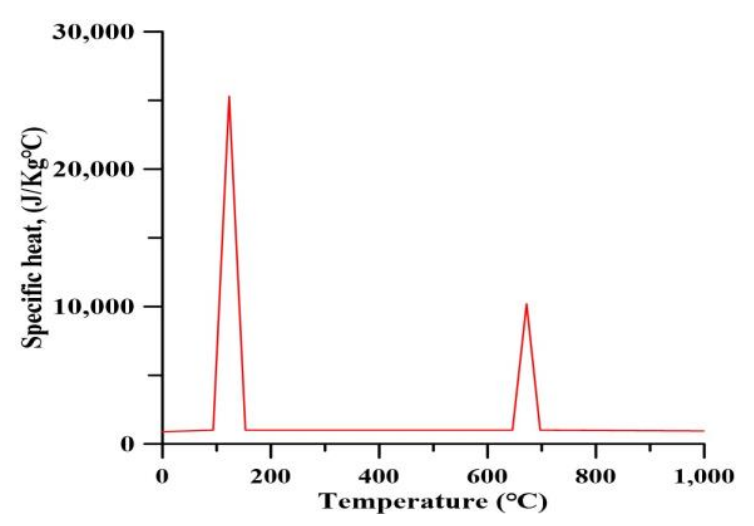

(b) Specific heat of gypsum board

Figure 4. Thermal properties of gypsum board.

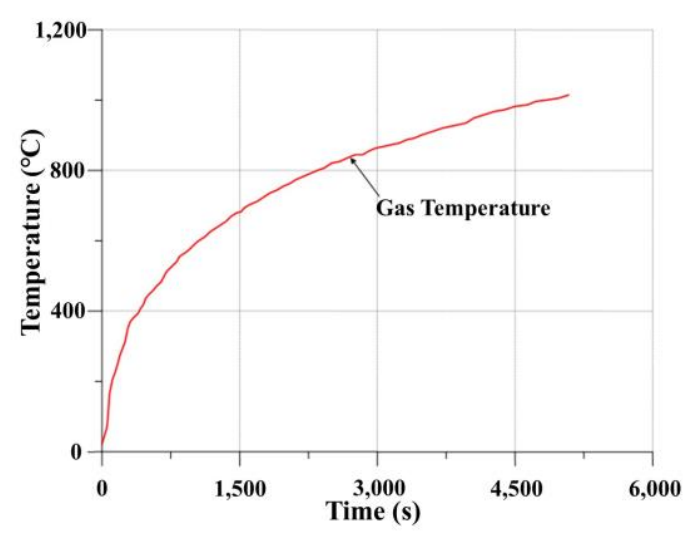

Figure 5. Thermal load history applied for the steel plate with PFP.

Figure 6 shows the comparison of the steel temperature with time between the LS-DYNA heat transfer analysis (using solid elements and shell elements) and the heat transfer equation method, with varying gypsum board thickness. For the relatively thin PFP, the results of shell element model were in good agreement with those of the solid element model by the heat transfer equation method. The comparison results show that modelling steel and PFP using shell elements in a single layer can reasonably accurately calculate the temperature of the steel plate. 


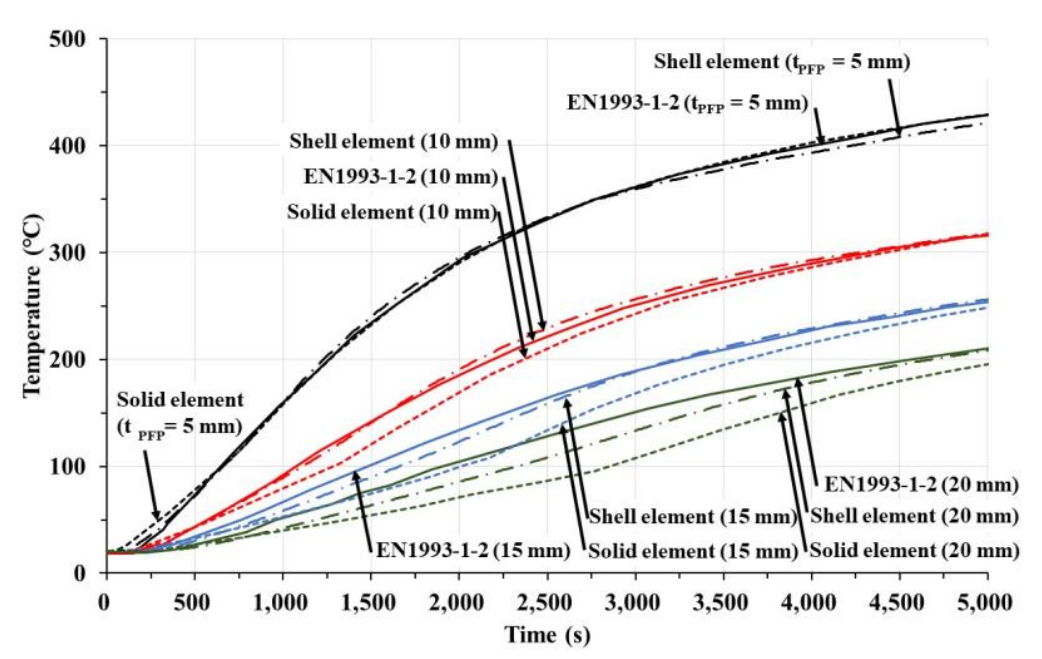

Figure 6. Comparison of temperature history between the numerical heat transfer analysis (using solid elements and shell elements) and the analytical equation method (EN1993-1-2), with varying gypsum board thickness.

\section{Application of the computational models to the tested structures}

The computational models presented in section 2 were applied to the fire-induced progressive collapse testing on full-scale steel stiffened plate structures without or with PFP under lateral patch loading. In the testing, the horizontal type fire test furnace in the ICASS/KOSORI in Hadong, South Korea (www.icass.certer) was used, as shown in Figure 7(a). Gas burners were used to increase the temperature inside the furnace. The loading actuators were used to apply external forces during fire testing. Figure 7(b) shows the tested structure on the furnace. Details of the test results are presented in Paik et al. [1,2].

During the process of welding fabrication, initial imperfections are inevitably developed in the form of initial deflections and residual stresses, which can significantly affect the ultimate strength under predominantly axial compressive loading, refer to the authors' articles [52-57] which are associated with the present paper. However, the tested structures under consideration were subjected to lateral patch loading at elevated temperatures, and the effects of initial imperfections on the structural collapse in fires are considered to be very small $[3,4,58]$. In this regard, the welding-induced initial imperfections were not measured.

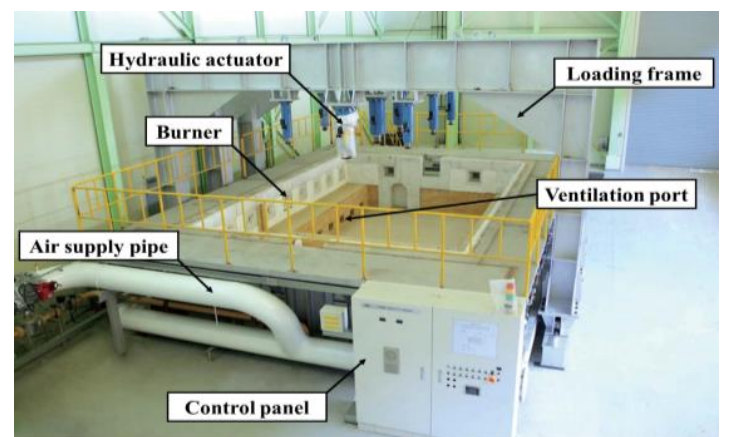

(a) Horizontal type fire test furnace

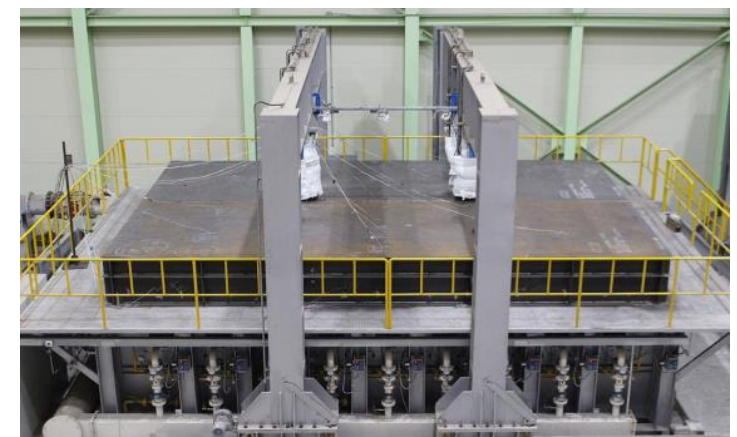

(b) Stiffened plate structure on the furnace 
Figure 7. Horizontal type fire test furnace and test set-up.

\subsection{Construction of the FE model}

LS-PrePost [50] for pre-processing and post-processing of LS-DYNA code was used to conduct the finite element analysis. It has advantages because multiple models are allowed to import and combine from various sources: LS-DYNA keyword, IDEAS neutral file, NASTRAN bulk data, STL ascii, and STL binary formats. The FE model of the tested structure was created by ANSYS Mechanical APDL, with which the information of the nodes and elements could be written as a file that can be read by the LS-PrePost program by using the Solution_Write Jobname.k function.

To make the model to be as close to the experimental conditions as possible, the tested structures with test jigs and the top of the fire test facility were included in the model. Because the four edges of the tested structures were welded to the test jigs as shown in Figure 8, the tested structure and the test jigs were modelled as one unit. To impart contact conditions between the test jigs and furnace, the top of the fire test facility was created $10 \mathrm{~mm}$ away from the test jigs considering the thickness of the steel plate. The top of the fire test facility was modelled in a size sufficiently wider than the area of the contacted test jigs, so it would not be penetrated by the node on the contact surface.

The tested structures included dummies and patch load plates and top of the fire test facility as shown in Figure 9. The dimensions of the tested structure, test jigs, patch load plates and dummies were presented in separate papers [1,2]. The size of steel patch load plates was $400 \mathrm{~mm} \times 400 \mathrm{~mm} \times 30 \mathrm{~mm}$ and the steel plate with a thickness of $10 \mathrm{~mm}$.
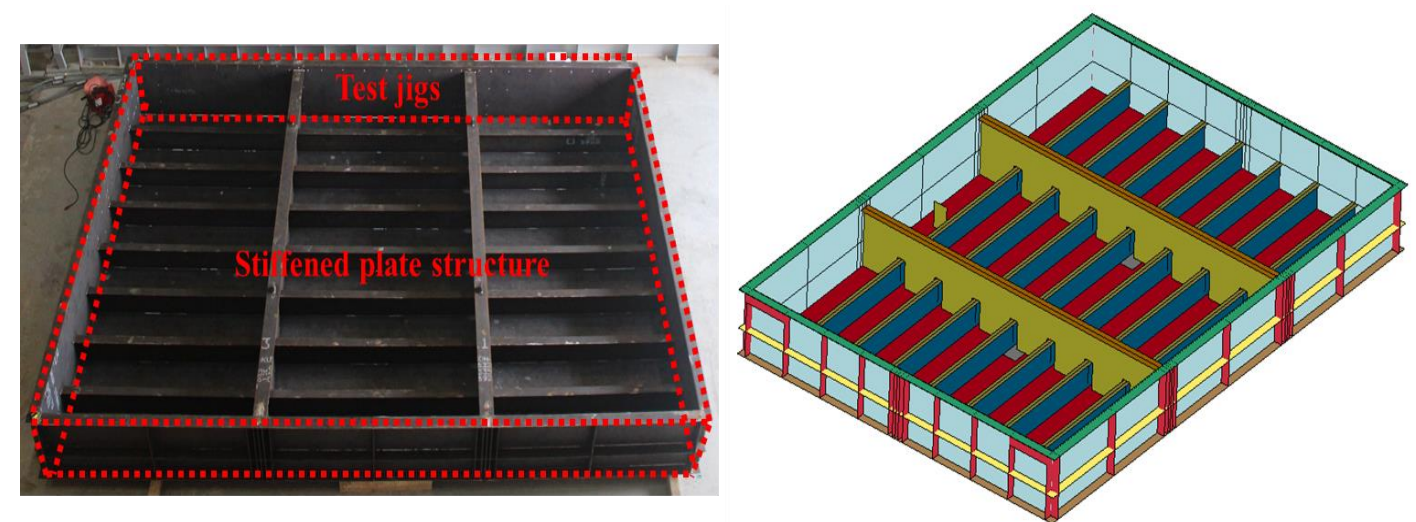

Figure 8. The tested structure (left) and the FE model (right) 


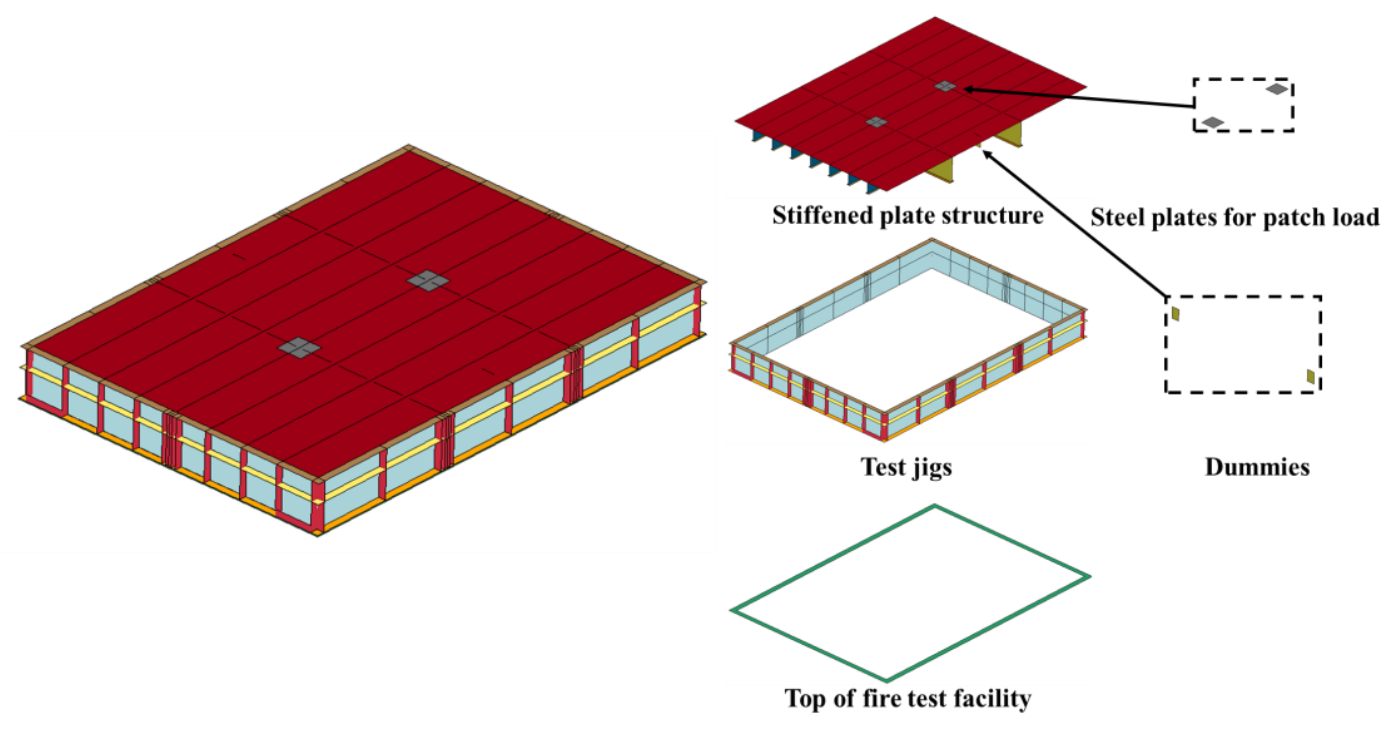

Figure 9. Composition of the geometry for the finite element model.

\subsubsection{Test structure without PFP}

The first test structure had no PFP [1], but two transverse frames of the second test structure were protected by PFP [2]. PFP was modelled using shell elements together with PART_PART function in LS-PrePost. This function allowed the users to characterize each part of the structures by entering the mechanical material property ID (MID), thermal material property ID (TMID), and member section information ID (SECID) containing thickness information for the selected member. In addition, all members were given $10 \mathrm{~mm}$ thickness, except the stiffened plate structure welded with patch load plates. Since the whole test structures were modelled using single-layer shell elements, the thickness of the shell elements representing stiffened plate structure welded with patch loads plates was given $40 \mathrm{~mm}(30 \mathrm{~mm}$ patch load plate and $10 \mathrm{~mm}$ stiffened plate structure). The mechanical and thermal properties of the material were defined in the MAT function, and the member section information of the shell elements was defined in SECTION_SHELL.

\subsubsection{Test structure with PFP}

Steel plate members with PFP were modelled using shell elements, where the PART_COMPOSITE function, the thickness of the material (THICK), the mechanical material property ID (MID), and thermal material property ID (TMID) of the steel and PFP were entered separately. In this function, member information was defined in correspondence with the normal vector of each member, so it is essential to secure the normal vector of each member at the modelling stage. In the FE model of the tested structure with PFP, the PART_COMPOSITE function was used for the plate members of the test jigs and the two transverse frames where the PFP was applied. The CONTACT_AUTOMATIC_SURFACE_TO_SURFACE_COMPOSITE function was used to apply the contact condition between the transverse frames and the longitudinal stiffeners until the structure collapsed. Since it is a function that can only be used between the members defined as the composite type, the longitudinal 
stiffeners were also applied with the PART_COMPOSITE function, except there is only one layer since there is no PFP on longitudinal stiffeners. For more accurate shell element response calculation, the CONTROL_SHELL function is used. The ISTUPD option was activated to apply the shell thickness change for deformable shell element, and the THSHEL option was activated to calculate the temperature gradient through the shell element thickness.

The same FE model was used to perform both heat transfer analysis and structural response analysis simultaneously. The mesh created for heat transfer analysis and structural response analysis is shown in Figure 10. The tested structure with the test jigs FE model consisted of 47,027 nodes and 47,090 shell elements. Most mesh size was $50 \mathrm{~mm} \times 50 \mathrm{~mm}$, except for some parts where smaller mashes were required. Figure 11 shows the distribution of maximum and minimum side length of each element.
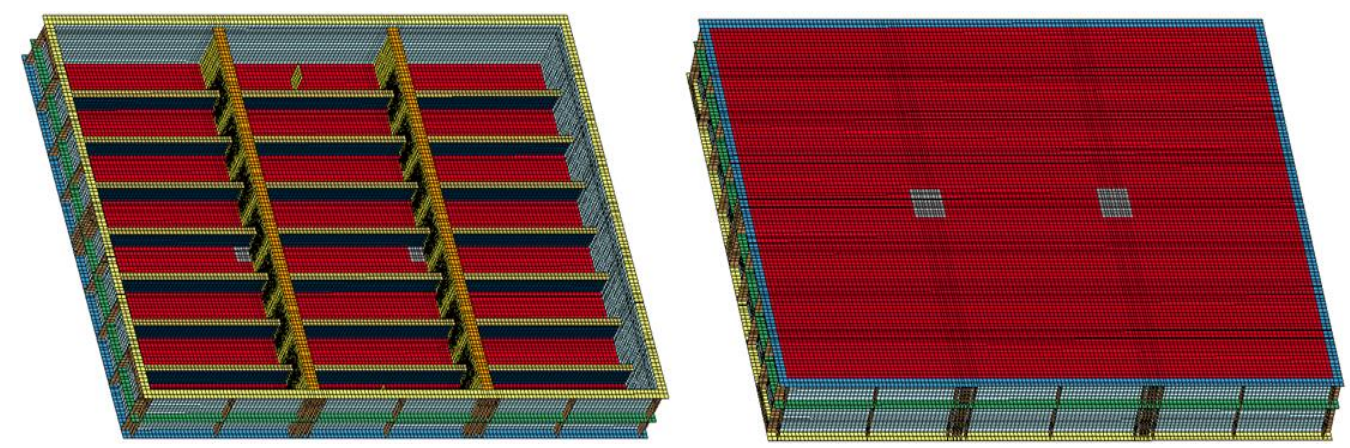

Figure 10. FE model for heat transfer analysis and structural response analysis.
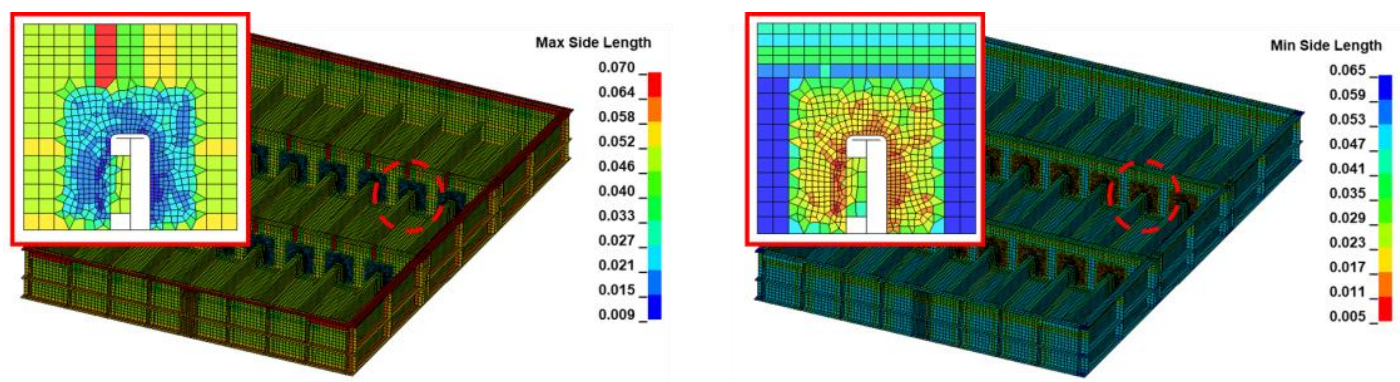

Figure 11. Distribution of maximum and minimum side length of each element.

\subsection{Mechanical properties at elevated temperature}

According to EN1993-1-2, the strain range between yield strain and limiting strain for yield strength was chosen since at this branch the steel structure is at effective yield strength state where the hardening modulus (tangent modulus) is 0 . Then, the reduction factors of stress-strain relationship of carbon steel at elevated temperatures were provided by EN1993-1-2. As discussed in Paik et al. [1,2], the EN1993-1-2 guidance of the reduction factor was confirmed to be in good agreement with material test data. Hence, the mechanical properties of steel at elevated temperature were defined from the reduction factor of EN1993-1-2 [42]. In LS-PrePost, mechanical properties of materials were defined up to eight different temperatures using the 
MAT_004-ELASTIC_PLASTIC_THERMAL function. Table 3 shows the input values for the function.

Table 3. Mechanical properties of the $\mathrm{AH} 32$ for finite element analysis

\begin{tabular}{|c|c|c|c|c|c|c|c|}
\hline Temperature & $0{ }^{\circ} \mathrm{C}$ & $100{ }^{\circ} \mathrm{C}$ & $400{ }^{\circ} \mathrm{C}$ & $500{ }^{\circ} \mathrm{C}$ & $600{ }^{\circ} \mathrm{C}$ & $700{ }^{\circ} \mathrm{C}$ & $800{ }^{\circ} \mathrm{C}$ \\
\hline $\begin{array}{c}\text { Elastic } \\
\text { modulus } \\
(\mathrm{Pa})\end{array}$ & $2.240 \mathrm{e}+11$ & $2.240 \mathrm{e}+11$ & $1.568 \mathrm{e}+11$ & $1.344 \mathrm{e}+11$ & $6.943 \mathrm{e}+10$ & $2.912 \mathrm{e}+10$ & $2.016 \mathrm{e}+10$ \\
\hline $\begin{array}{c}\text { Yield stress } \\
(\mathrm{Pa})\end{array}$ & $3.396 \mathrm{e}+08$ & $3.396 \mathrm{e}+08$ & $3.396 \mathrm{e}+08$ & $2.649 \mathrm{e}+08$ & $1.596 \mathrm{e}+08$ & $7.810 \mathrm{e}+07$ & $3.735 \mathrm{e}+07$ \\
\hline $\begin{array}{c}\text { Hardening } \\
\text { modulus } \\
(\mathrm{Pa})\end{array}$ & $1.000 \mathrm{e}-10$ & $1.000 \mathrm{e}-10$ & $1.000 \mathrm{e}-10$ & $1.000 \mathrm{e}-10$ & $1.000 \mathrm{e}-10$ & $1.000 \mathrm{e}-10$ & $1.000 \mathrm{e}-10$ \\
\hline
\end{tabular}

The properties of PFP were defined using the MAT_004-ELASTIC_PLASTIC_THERMAL function. The PFP material used in this study was a product called cerakwool, and its yield strength at room temperature is $0.75 \mathrm{MPa}$. The strength of the PFP was negligible because it was weak enough to be torn by bare hand. For this reason, Elastic modulus and hardening modulus values were assumed to be 1 and $10^{-9}$, respectively. The thermal properties of steel and PFP were defined by loading the specific heat curve and the thermal conductivity curve under elevated temperature into the computational model using MAT_T10-THERMAL_ISOTROPICTD_LC function. The curve ID was defined in DEFINE_CURVE function. The thermal properties of steel and PFP are presented in detail through the experiment papers $[1,2]$.

\subsection{Boundary conditions}

The boundary conditions applied for the LS-DYNA analysis are described in Figure 12. The welded sections to fix the test jigs on the furnace were given fixed conditions, and the top of the fire test facility mentioned before was modelled and assumed to be a rigid body. The dimensions of the welded sections were described in the experiment paper [1,2]. The BOUNDARY_SPC_SET function can be used to input the translational constraint and rotational constraint on required sections (welded sections). 

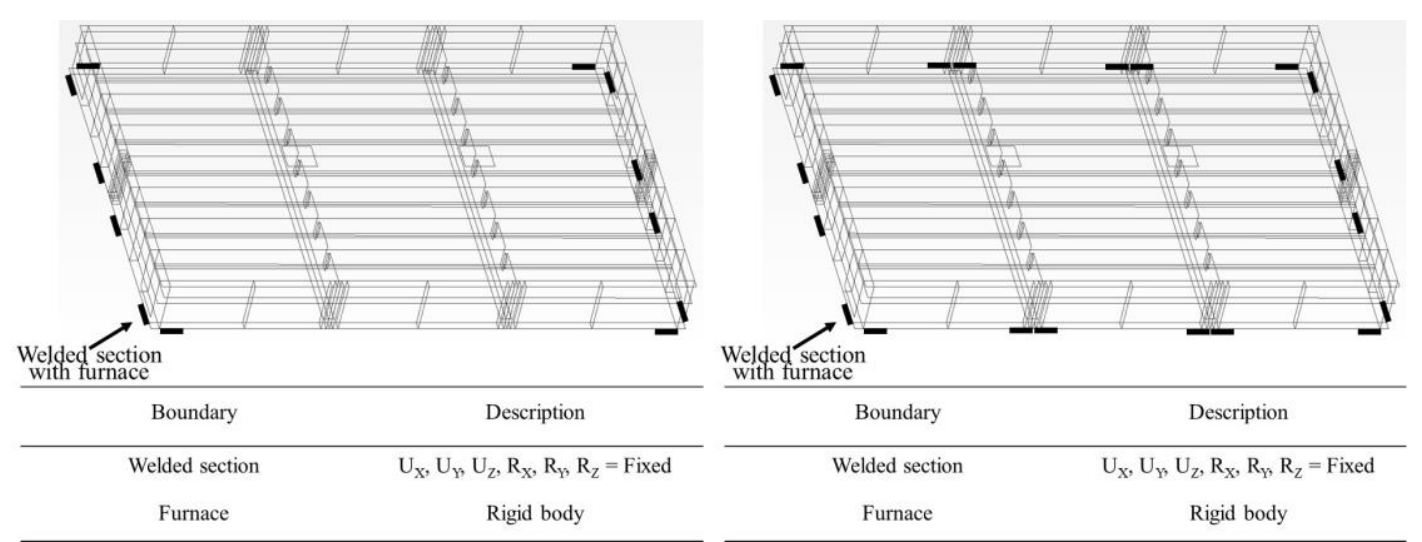

Figure 12. Boundary conditions of FEA for the test structure without PFP (left) and with PFP (right)

The lateral deformation of the tested structures occurred, and the structural members were in contact with one and another, and thus the contact condition was considered to prevent the node of one member from penetrating another member to affect the accuracy of the simulation. The CONTACT_AUTOMATIC_SINGLE_SURFACE function was used for the contact condition between the test jigs and the top surface of the horizontal fire test facility. When the tested structures collapsed, the contact condition between the transverse members and the longitudinal members were also considered. For the FE model without PFP on the transverse frames, the contact condition was assigned using the CONTACT_AUTOMATIC_SINGLE_SURFACE function in the same way as the contact condition between the test jigs and the top surface of the fire test facility. For the FE model with PFP on the transverse frames, the CONTACT_AUTOMATIC_SURFACE_TO_SURFACE_COMPOSITE function was used because of the transverse frames with PFP was modelled using the PART_COMPOSITE function. The commonly used static and dynamic coefficient of friction was used as 0.3 [4]. The default values for computation with contact surfaces were applied using the CONTROL_CONTACT function.

\subsection{Gas cloud temperature}

The fire CFD simulation was not performed to identify the distribution of gas cloud temperature in the present study. Instead, the gas cloud temperature measured from the tests was used for the heat transfer analysis to define the steel temperature, and it was assumed that the gas temperature distribution is uniform over the structures. The tests were terminated after the collapse of the tested structures was reached, and the actuator and heat system was turned off. However, the FE analysis was continued until and after the tested structures collapsed. Figure 13 compares the gas temperature of tested structures with time. 


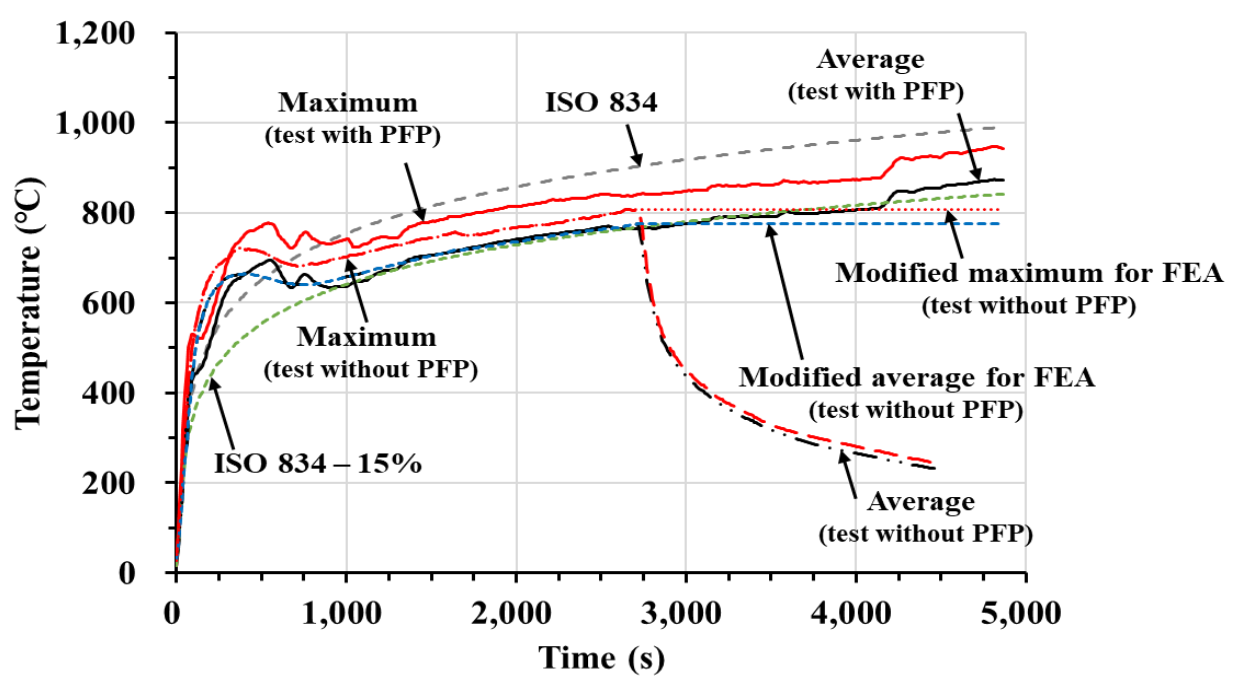

Figure 13. Comparison of gas cloud temperature between tests, computational models and ISO suggestions.

Heat loss on the side unexposed to fire was also considered, and the ambient room temperature was measured by the furnace facility during the tests and it was confirmed that the ambient room temperature distribution was almost uniform. In the tested structure without PFP, the ambient room temperature rose from $27.6{ }^{\circ} \mathrm{C}$ to $30.6{ }^{\circ} \mathrm{C}$ after an hour, and that with PFP, it was $17.6{ }^{\circ} \mathrm{C}$ to $22.6{ }^{\circ} \mathrm{C}$. The curves of the increased room temperature with time were described in the experiment papers [1,2].

For the heat transfer analysis, heat flux calculation conditions were defined. Heat flux was calculated by the sum of heat flux due to convection and heat flux due to radiation. The FE model developed in present study was composed of shell elements, and thus it was required to calculate the heat flux by convection and radiation on both sides, so a total of four calculation terms were inevitable. Heat flux calculation conditions were defined using the BOUNDARY_FLUX_SET function, which allowed the user to enter the convection and radiation coefficients on each side of the shell element.

The convection coefficient and the radiation coefficient were defined for the heat flux calculation conditions. In the present study, the convection coefficient of the unexposed side was taken as $h_{c}=10 \mathrm{~W} / \mathrm{m}^{2} \mathrm{~K}$, and the convection coefficient of the exposed side was taken as $h_{c}=19 \mathrm{~W} / \mathrm{m}^{2} \mathrm{~K}$ by engineering judgement [41]. The value of the radiation emissivity coefficient of steel was taken as $\varepsilon_{s}=0.24$, and the value of the radiation emissivity coefficient of the PFP was taken as $\varepsilon_{s}=0.90$ provided by the manufacturer. The initial temperature of the FE model was set to be $20{ }^{\circ} \mathrm{C}$ using the INITIAL_TEMPERATURE_SET function.

3.5 Lateral patch loads 
The lateral patch loads applied to the tested structure were defined in the FEA. The LOAD_BODY_Z function was used to impart gravity, and the BODY_NODE_SET function was used to impart the lateral patch loads at the centre of each transverse frame applied by the actuator. Unlike the actual experiments, the lateral patch loads were maintained even after the collapse of the test structure to continuously observe the progressive collapse behaviour. Figure 14 shows the patch loads applied at the centre of each transverse frame for the fire collapse analysis model of both experiments.

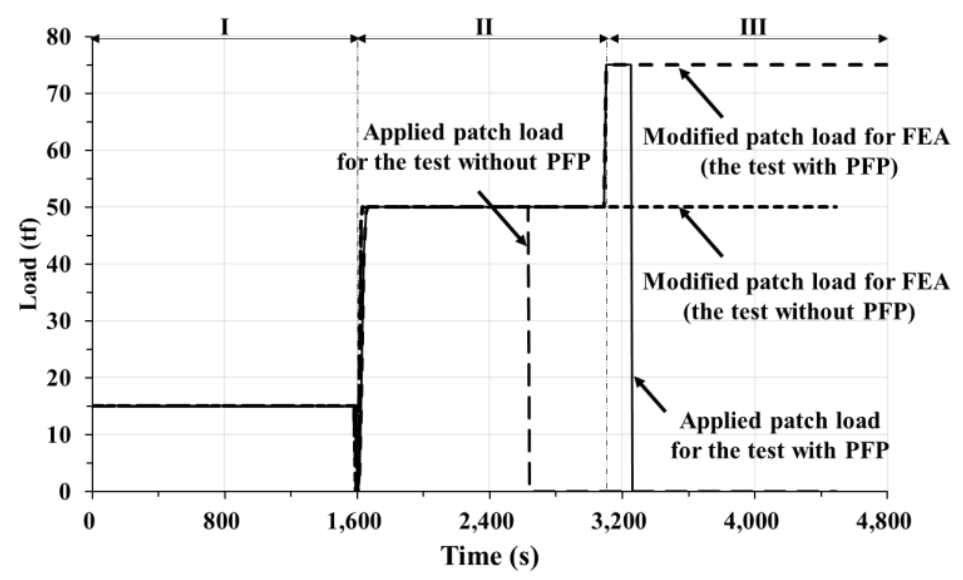

Figure 14. Three-phased model for assumed patch load history in the computational model.

\subsection{Other settings}

Using the CONTROL_SOLUTION function, 'Structural analysis only', 'Thermal analysis only', or 'Coupled structural thermal analysis' were selected and performed. To confirm the exact coefficient of the convection and the radiation for further finite element analysis, the average temperature data collected from the furnace test facility was first adopted for the heat transfer analysis by selecting the 'Thermal analysis only' option. For the coupled structural thermal analysis, the maximum temperature in the furnace was adopted since the tested structure was mainly affected by the maximum gas cloud temperature inside the furnace. Besides, the transverse frames which are the main structural members in the test were exposed closer to the location of the maximum temperature in the furnace.

During the actual physical model testing, for safety reasons, both experiments were terminated immediately after the collapse of the test structures, but for the numerical analysis, the structural response analysis was performed until 5,000 seconds to observe the behaviour of the structure after the collapse. Termination time was entered using the CONTROL_TERMINATION function. For the heat transfer analysis, the time step was set to be 1 second using the CONTROL_THERMAL_TIMESTEP function. Other detailed settings for the heat transfer analysis were set using CONTROL_THERMAL_NONLINEAR and CONTROL_THERMAL_SOLVER functions. 
The numerical algorithms for structural response analysis can be classified into the implicit analysis and explicit analysis procedure depending on the differential equation analysis method. The present study used the implicit finite element techniques, which have a relatively high accuracy of analysis results by calculating stable response of structure over time, and with less constraint on element size or time interval [51]. The implicit analysis method was applied with the IMFLAG value as 1, and the time step was applied as 50 seconds with the DT0 value as 50 in the CONTROL_IMPLICIT_GENERAL function. To control the implicit nonlinear method, the parameters were used with the CONTROL_IMPLICIT_SOLUTION and CONTROL_IMPLICIT_SOLVER function. In case an error occurred due to a convergence problem, various tolerance values were modified.

\section{Computational results and discussion}

Figure 15 compares the temperature history of the tested structure without PFP, obtained from the test [1] and predicated using the LS-DYNA heat transfer analysis. The temperature of the structure calculated through heat transfer analysis is very well matched with the temperature measured in the test. After 2,720 seconds the heat system was shut down in the test, but in the computational model, the temperature of the structure was continued to observe without reducing the heat loads. The temperature of the transverse frames was obtained by the heat transfer analysis, it reached $600{ }^{\circ} \mathrm{C}$ at 1,300 seconds, which means that the remaining yield strength of the transverse frames was $47 \%$ of the original yield strength.
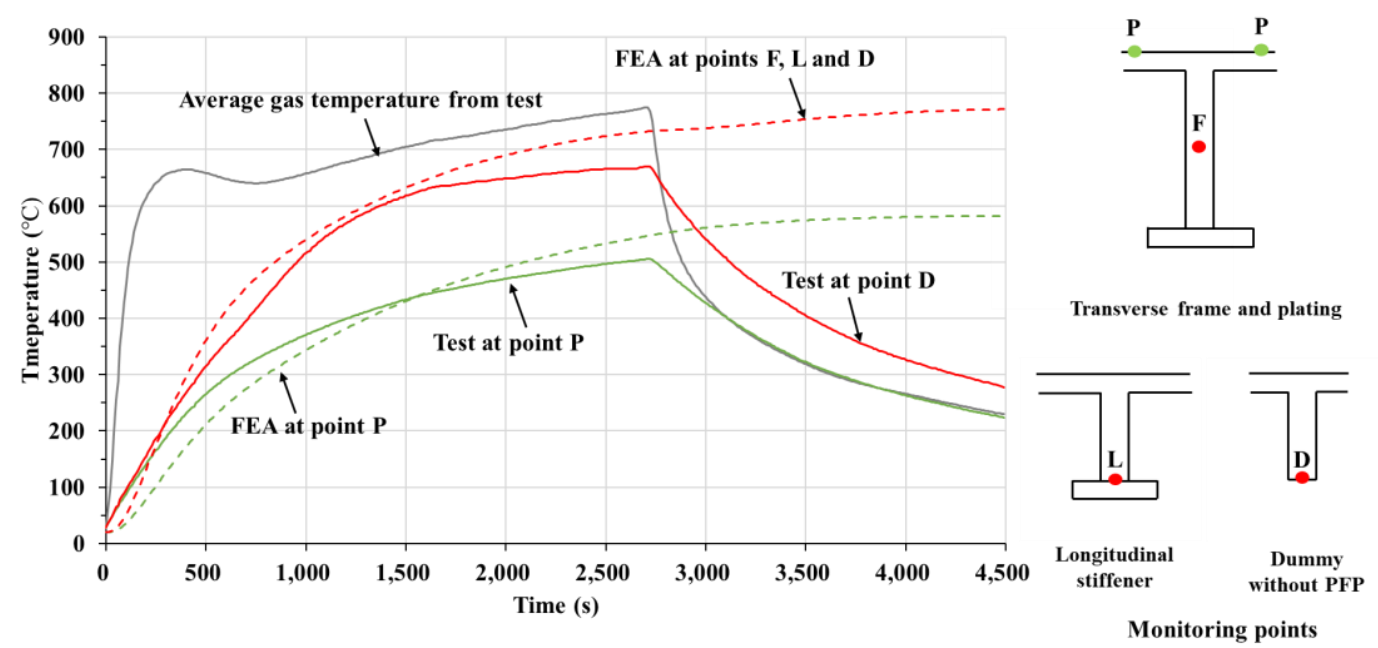

Figure 15. Comparison of the structure temperature between the test without PFP and computational model.

Figure 16 compares the temperature variation of the tested structure with PFP obtained from the test [2] and the LS-DYNA heat transfer analysis. The temperature of the structure calculated through heat transfer analysis is very well matched with the temperature measured in the tests. After 4,860 seconds the heat system was shut down 
in the test, but in the computational model, the temperature of the structure was continued to observe without reducing the heat loads. The temperature of the transverse frame obtained by the heat transfer analysis did not reach $300{ }^{\circ} \mathrm{C}$ even after 4,000 seconds.
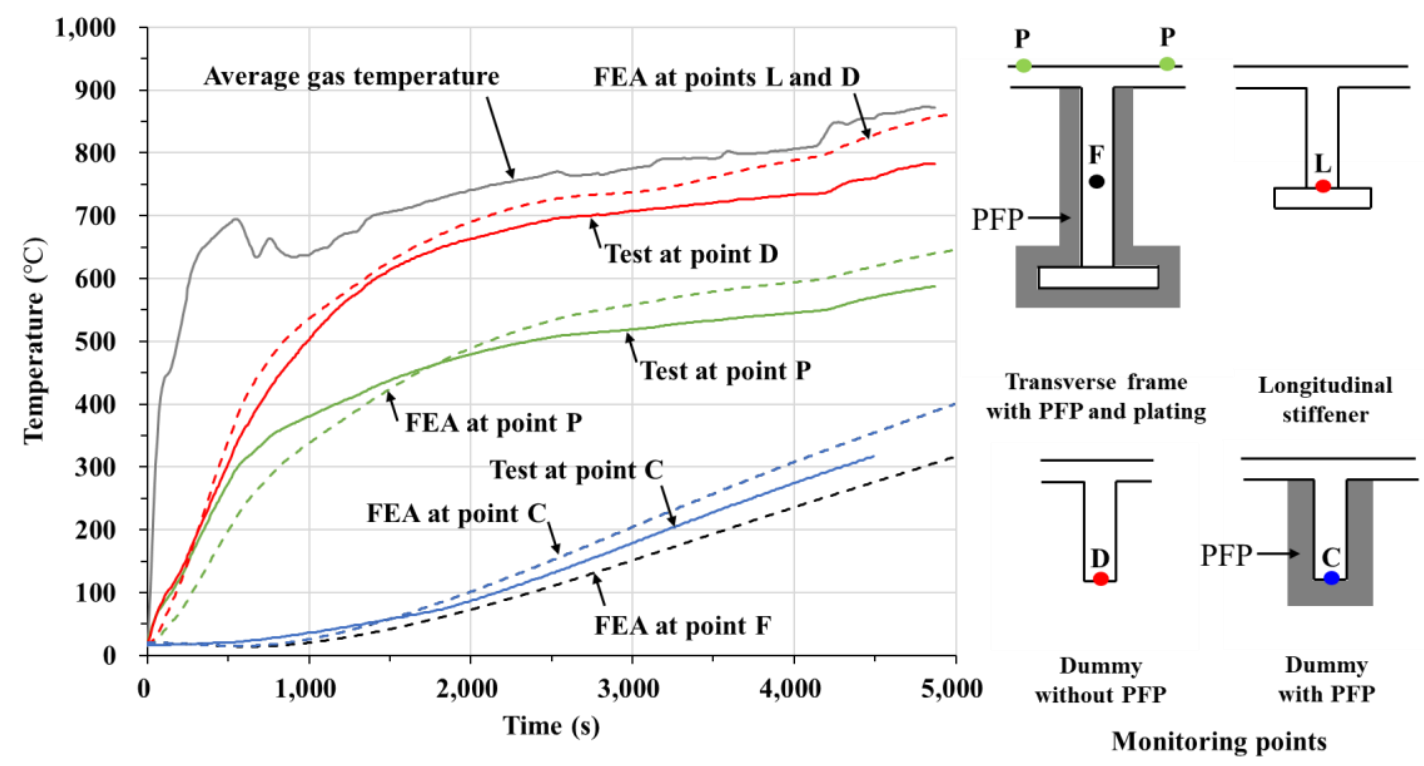

Figure 16. Comparison of the structure temperature between the test with PFP and computational model.

Since the fire collapse of the structure is triggered by the highest temperature, the maximum gas temperature inside the furnace was used for structural response analysis. Figure 17 compares the lateral deformation at the centre of the transverse frame of the stiffened plate structure without or with PFP between the tests and the LS-DYNA nonlinear structural response analyses. The computations of the LS-DYNA analyses are in good agreement with the tests. Again, lateral deformations in the computations continued to increase since, unlike tests, heat loads and patch loads were not removed after the collapse of the structure. 


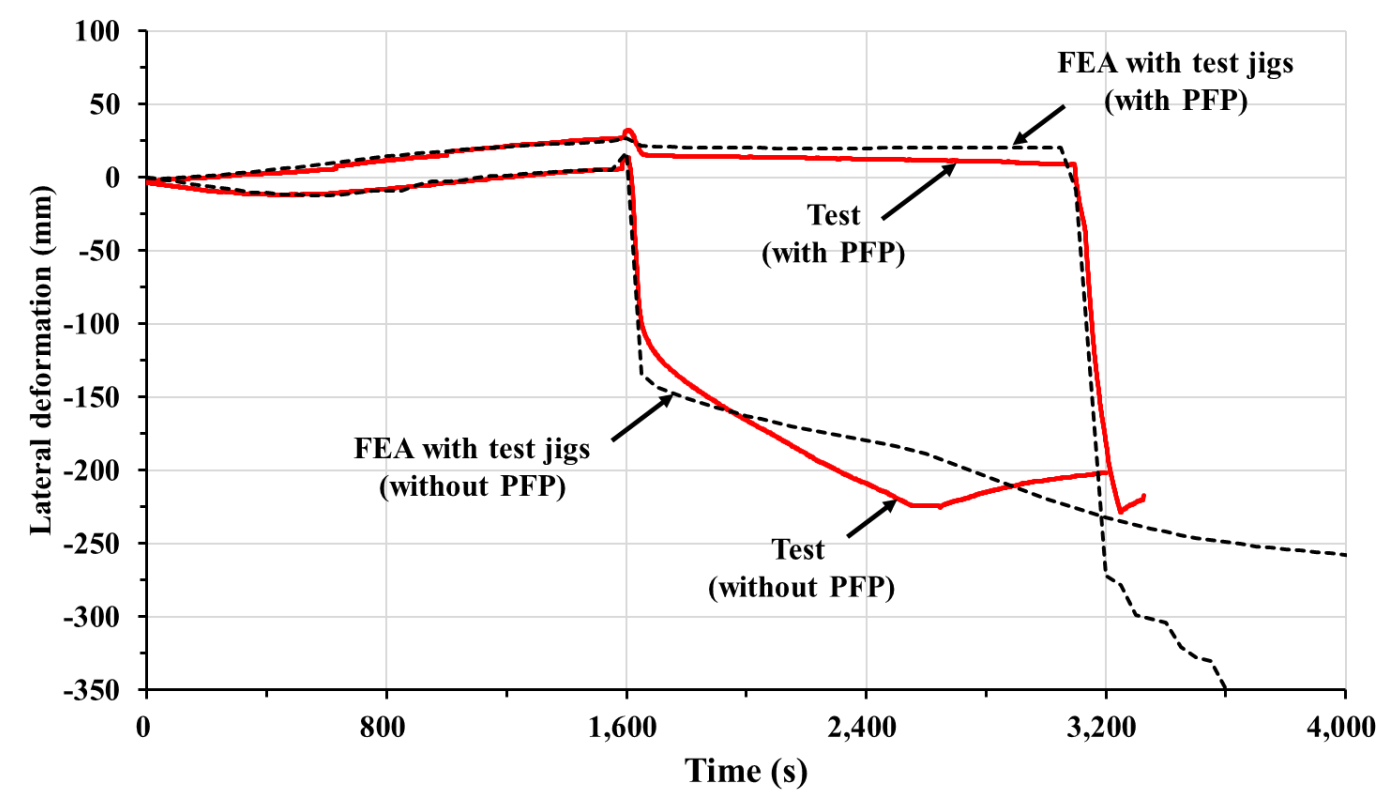

Figure 17. Comparison of the lateral deformation at the centre of the transverse frame of the structure with or without PFP between the computation versus the test.

Figures 18 and 19 show the comparison of the deformed shape between the test and the computation with or without PFP after the collapse of the tested structure, showing a good agreement. It is clearly found that the collapse of the structure with PFP was delayed, and longitudinal stiffeners were exposed to heat for a longer period, resulting in the deformation greater than the structure without PFP.
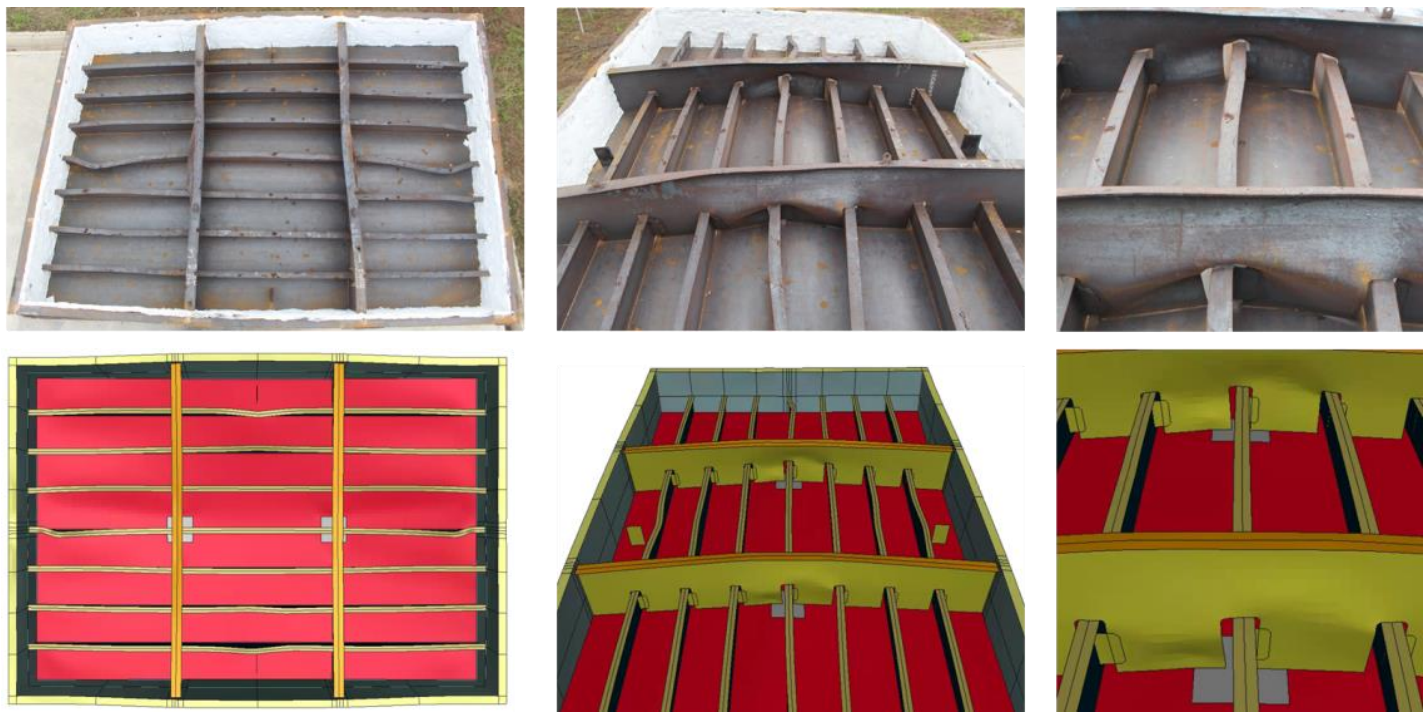

Figure 18. Comparison of the deformed shape for the structure without PFP after the collapse between the tested structure and the computation. 

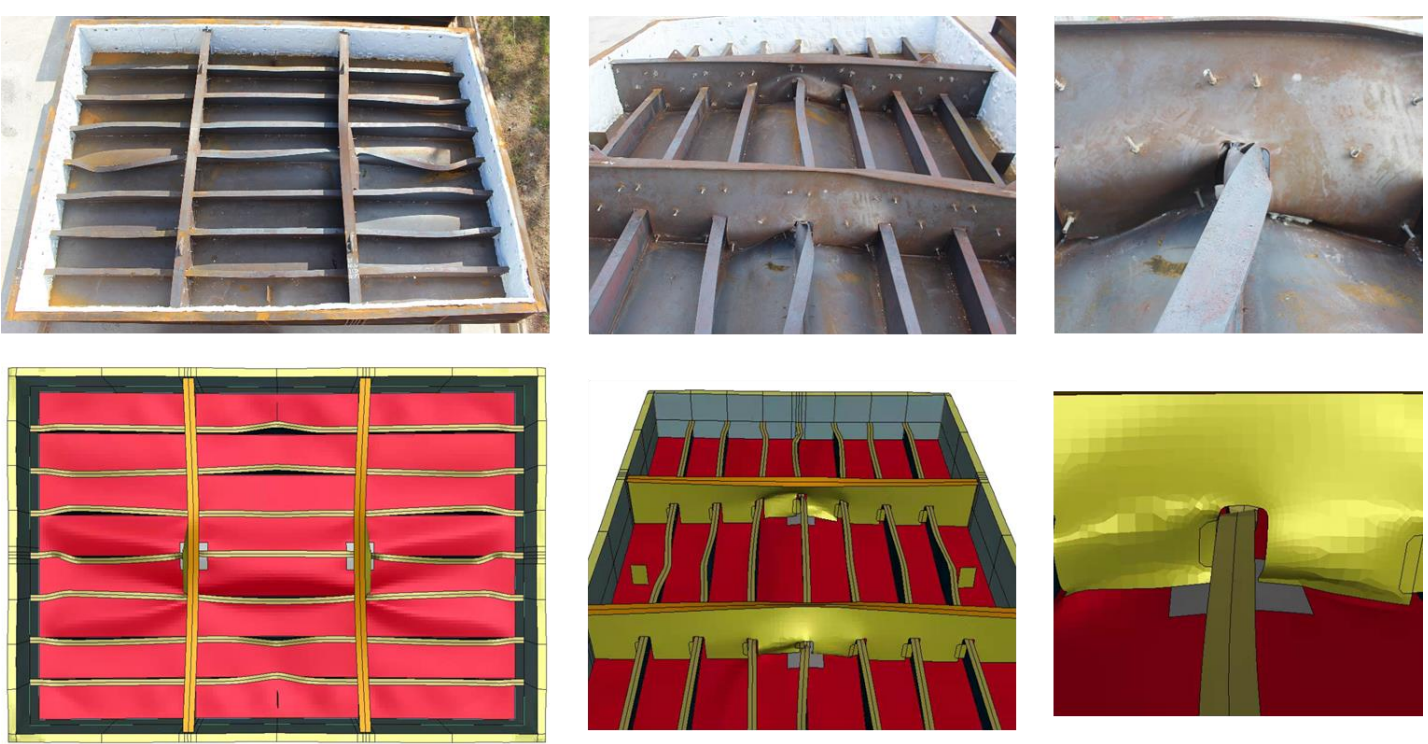

Figure 19. Comparison of the deformed shape for the structure with PFP after the collapse between the tested structure and the computation.

To confirm the effect of PFP more precisely, the boundary conditions of the two computational models were kept the same and the influence of the test jigs in deformation was eliminated. Since the four edges of the tested structures were fixed by the test jigs, the computational analyses used the same conditions as shown in Figure 20. Figure 21 shows the comparison of transverse frame temperature without and with PFP as obtained from the computations. For the structure without PFP, the temperature of transverse frames reached $600^{\circ} \mathrm{C}$ at 1,050 seconds. On the other hand, the temperature of transverse frames for the structure with PFP was kept under $200^{\circ} \mathrm{C}$ until 3,000 seconds.

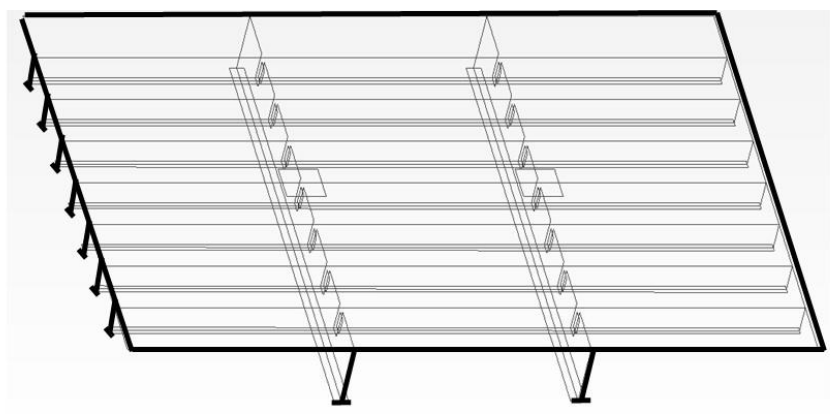

\begin{tabular}{cc}
\hline Boundary & Description \\
\hline 4 Edges & $\mathrm{U}_{\mathrm{X}}, \mathrm{U}_{\mathrm{Y}}, \mathrm{U}_{\mathrm{Z}}, \mathrm{R}_{\mathrm{X}}, \mathrm{R}_{\mathrm{Y}}, \mathrm{R}_{\mathrm{Z}}=$ Fixed
\end{tabular}

Figure 20. Computational model of the steel stiffened plate structure without test jigs. 


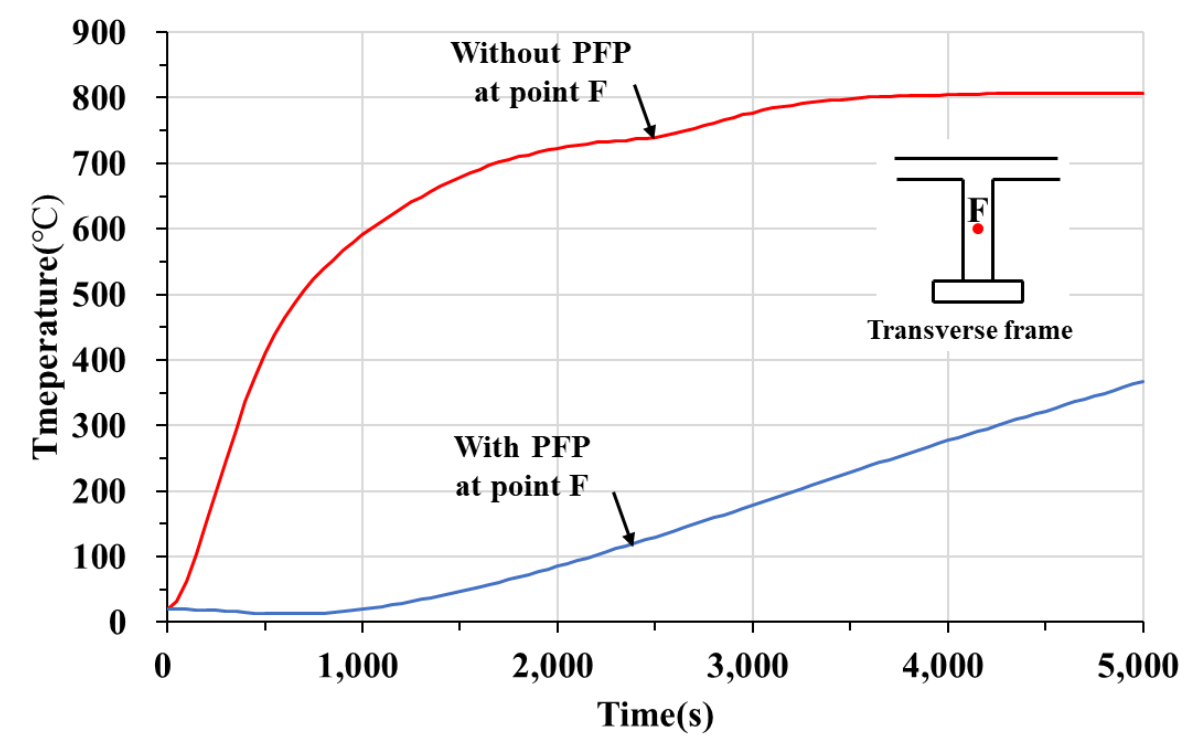

Figure 21. Comparison of transverse frame temperature of the structure without PFP versus with PFP as obtained from the computations.

As the steel temperature increases, the steel structure loses the strength of the member, which can easily lead to collapse. The deformation of the stiffened plate structures according to PFP at 500 seconds, 1,600 seconds, and 3,000 seconds are shown in Figures 22, 23 and 24. The transverse frames protected by PFP remained at low temperature, with small deformation. This means that PFP is an effective option to delay the collapse of the structure. Comparing the lateral deformation at the centre of the transverse frame without and with PFP, the effect of the PFP is straightforward on the fire-induced progressive collapse of steel stiffened plate structures as shown in Figure 25. The structure without PFP reached the collapse under a patch load of $100 \mathrm{tf}$ at 1,630 seconds. In the same condition, however, the structure with PFP was still intact with a small deformation of $23 \mathrm{~mm}$ and eventually reached the collapse at 3,050 seconds.
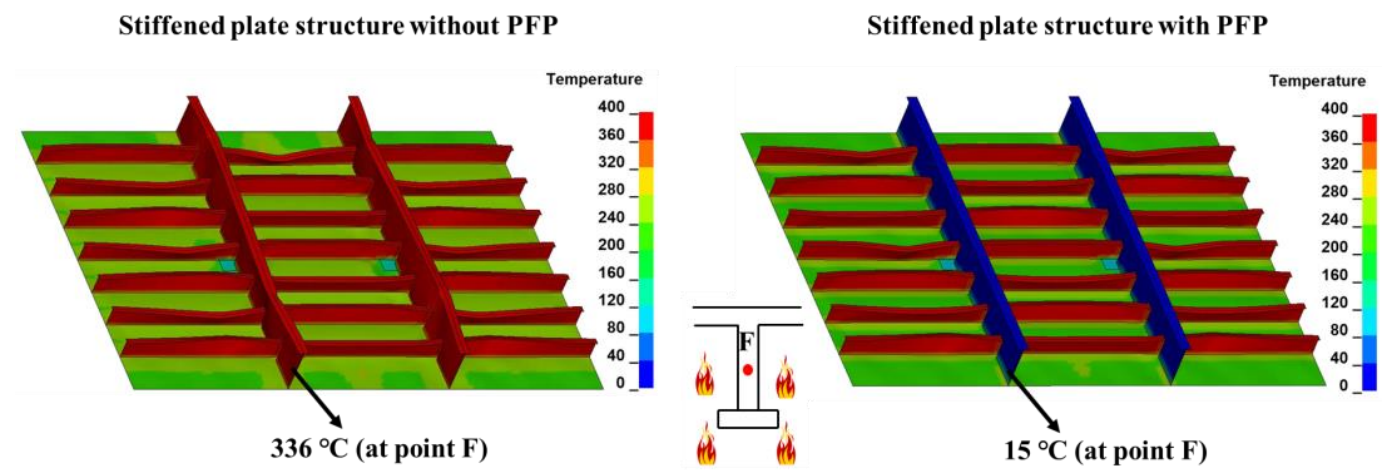

Figure 22. Comparison of steel temperature distributions and deformation after 500 seconds in computational model. 


\section{Stiffened plate structure without PFP}

Stiffened plate structure with PFP
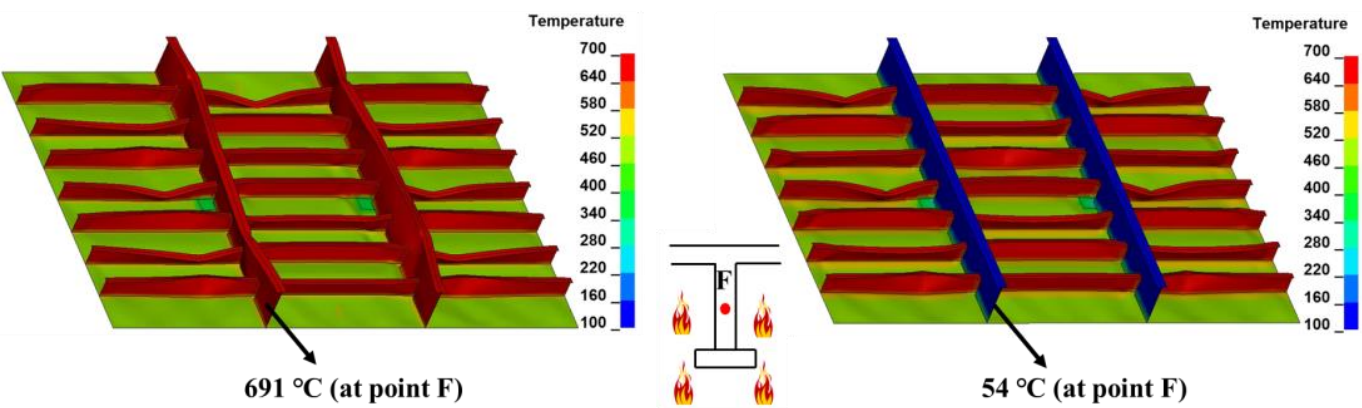

Figure 23. Comparison of steel temperature distributions and deformation after 1,600 seconds in computational model.

Stiffened plate structure without PFP

Stiffened plate structure with PFP
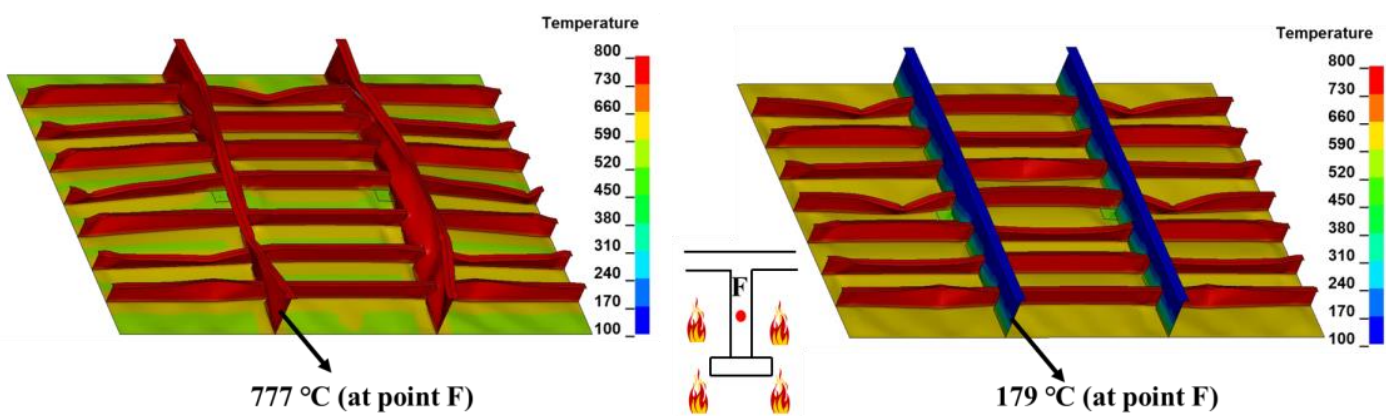

Figure 24. Comparison of steel temperature distributions and deformation after 3,000 seconds in computational model.

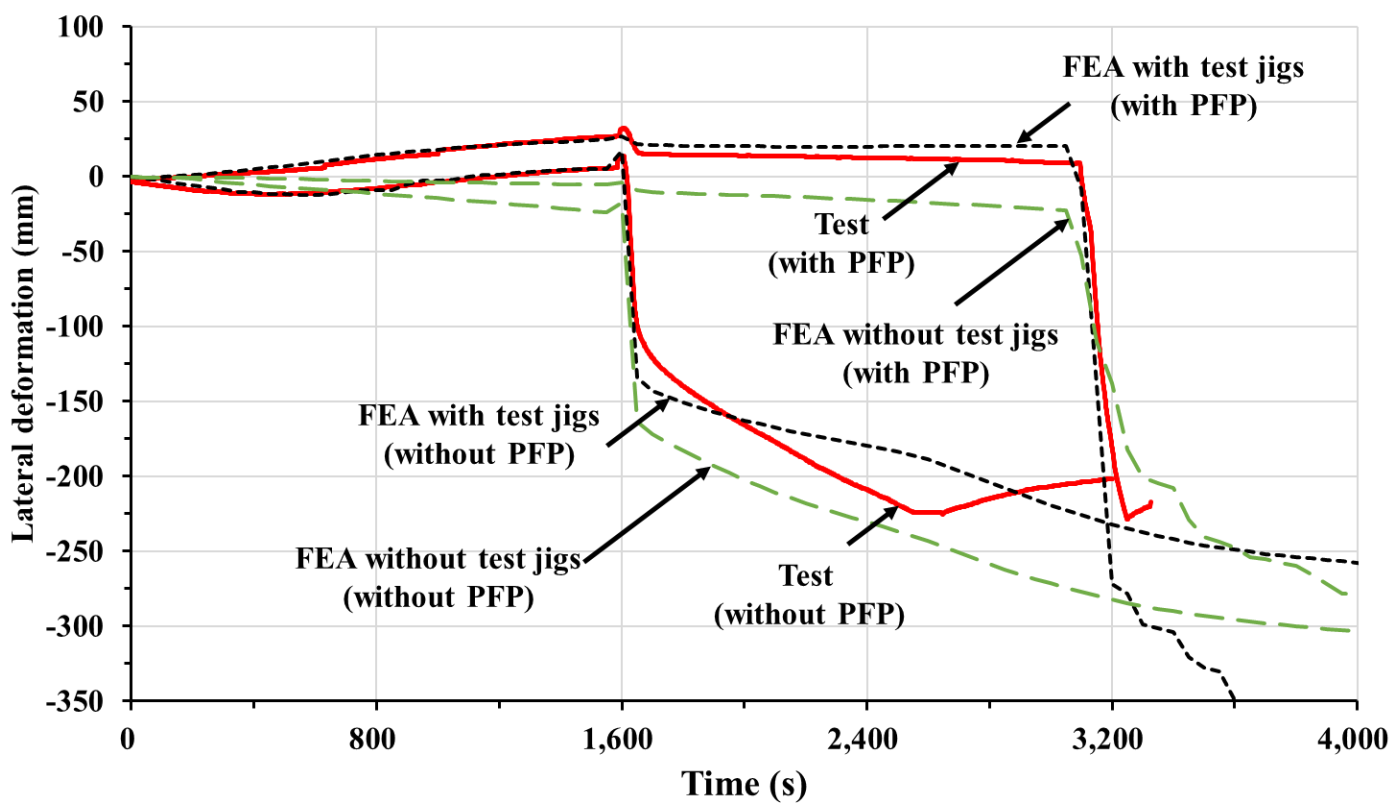

Figure 25. Comparison of the lateral deformation at the centre of the transverse frame without PFP versus with PFP. 
For the structure with and without PFP, compare the deformed shape during two lateral patch load phases: 500 seconds to 1,600 seconds (maintained at 15tf), 1,600 seconds to 3,000 seconds (maintained at 50tf). It is obvious that the different plate members suffered significant deformations even though the lateral patch loading was kept constant. This means that as the steel temperature increases, the steel structure continues to lose its strength lead to the structural members collapse progressively regardless the external force. In addition, progressive collapse results when an initially localized failure of a structural element, in this case the two transverse frames, propagates to other elements leading to a boarder structural failure.

\section{Concluding remarks}

The objective of the present study was to establish a procedure for the nonlinear computations of the fire-induced progressive collapse behavior for steel stiffened-plate structures without or with passive fire protection (PFP). Nonlinear finite element method computational modelling techniques for both the heat transfer analysis and the thermal elastic-plastic large-deformation analysis were developed, and they were validated with a comparison with the experimental data which was obtained from the fire-induced progressive collapse tests on full-scale steel-stiffened plate structures without and with PFP under lateral patch loadings [1,2]. Based on the study, the following conclusions and insights can be drawn.

(1) Only shell elements were used to model both plating, and both web and flange of stiffeners. Also, PFP was modelled using a single layer shell element instead of solid element. It was confirmed that this modelling technique is successful for both the heat transfer analysis and the nonlinear structural response (fire-induced progressive collapse) analysis.

(2) Heat fluxes are transferred from fire to the surrounding structures in association with convection and radiation. For the heat transfer analysis, the convection heat transfer coefficient and radiation emissivity coefficient should be defined properly because they significantly affect the heat transfer characteristics.

(3) Similar to the progressive collapse analysis of steel plated structures at room temperature, not only geometric properties but also material properties should be defined accurately. To account for the fact that the material properties are significantly reduced at elevated temperatures, the reduction factor of the material properties suggested by the EN 1993-1-2 is useful to apply.

(4) For fire safety engineering, not only the fire collapse loads but also the critical period of time until the collapse is reached should be determined. This critical time period is important for establishing the safety scheme of escape and evacuation.

(5) For the quantitative fire risk assessment, fire consequences should be quantified accurately.

(6) The computational models developed in the present paper will be useful for above purposes. 


\section{Acknowledgements}

The present study was conducted at the Korea Ship and Offshore Research Institute (International Centre for Advanced Safety Studies) at Pusan National University in South Korea which has been a Lloyd's Register Foundation Research Centre of Excellence since 2008.

\section{ORCID}

Jeom Kee Paik: http://orcid.org/0000-0003-2956-9359

Giles Thomas: http://orcid.org/0000-0002-6122-4329

\section{References}

[1] J.K. Paik, M.G. Ryu, K. He, D.H. Lee, S.Y. Lee, D.K. Park, G. Thomas, Full-scale fire testing to collapse of steel stiffened plate structures under lateral patch loading (Part 1) - without passive fire protection, Ships and Offshore Structures, doi: 10.1080/17445302.2020.1764705, 2020.

[2] J.K. Paik, M.G. Ryu, K. He, D.H. Lee, S.Y. Lee, D.K. Park, G. Thomas, Full-scale fire testing to collapse of steel stiffened plate structures under lateral patch loading (Part 2) - with passive fire protection, Ships and Offshore Structures, doi: 10.1080/17445302.2020.1764706, 2020.

[3] J.K. Paik, Ultimate limit state analysis and design of plated structures, $2^{\text {nd }}$ Edition, John Wiley \& Sons, Chichester, UK, 2018.

[4] J.K. Paik, Advanced structural safety studies with extreme conditions and accidents, Springer, Singapore, 2020.

[5] F. Evegren, Fire risk assessment of alternative ship design, Ships and Offshore Structures, 12(6): 837-842, 2017.

[6] J.K. Paik, B.J. Kim, J.S. Jeong, S.H. Kim, Y.S. Jang, G.S. Kim, J.H. Woo, Y.S. Kim, M.J. Chun, Y.S. Shin, CFD simulations of gas explosion and fire actions, Ships and Offshore Structures, 5(1): 3-12, 2010.

[7] A.M. Salem, E.M. Dabess, A.A. Banawan, H.W. Leheta, Fire safety design of Nile-floating hotels, Ships and Offshore Structures, 11(5): 482-500, 2016.

[8] J. Zhang, S. Lu, C. Li, R.K.K. Yuen, Performance of overall heat transfer coefficient and exploring heat transfer through the ceiling vent of compartment fire in ship structures with A60 constructions, Ships and Offshore Structures, 10(3): 328-334, 2015.

[9] A. Salem, Fire engineering tools used in consequence analysis, Ships and Offshore Structures, 5(2): 155-187, 2010.

[10] E. Akyuz, E. Celik, M. Celik, A practical application of human reliability assessment for operating procedures of the emergency fire pump at ship, Ships and Offshore Structures, 13(2): 208-216, 2017.

[11] J.K. Seo, D.C. Kim, Y.C. Ha, B.J. Kim, J.K. Paik, A methodology for determining efficient gas detector locations on offshore installations, Ships and Offshore Structures, 8(5): 524-535, 2013.

[12] Y. Cao, A. Liu, M. Chen, Y. Jiang, S. Wang, Y. Bai, Safety analysis of an offshore platform for leakage and deflagration accidents from adjacent oil and gas 
storage and transportation units, Ships and Offshore Structures, doi: 10.1080/17445302.2020.1786234.

[13] G. Lou, C. Wang, J. Jiang, Y. Jiang, L. Wang, G. Li, Fire tests on full-scale steel portal frames against progressive collapse, Journal of Constructional Steel Research, 145: 137-152, 2018.

[14] R. Suwondo, L. Cunningham, M. Gillie, C. Bailey, Progressive collapse analysis of composite steel frames subject to fire following earthquake, Fire Safety Journal, 103: 49-58, 2019.

[15] N. Parthasarathi, K. Thiagarajan, K.S. Satyanarayanan, V. Thamilarasu, Nonlinear analysis of the progressive collapse for two-dimensional steel frame under fire conditions, Materialstoday Proceedings, 5(2:3): 8718-8726, 2018.

[16] J. Jiang, G. Li, Progressive collapse analysis of 3D steel frames with concrete slabs exposed to localized fire, Engineering Structures, 149: 21-34, 2017.

[17] D. Isobe, Chapter six - fire-induced progressive collapse analysis of high-rise buildings, Progressive Collapse Analysis Structures: Numerical Codes and Applications, Butterworth Heinemann, 59-66, doi: 10.1016/B978-0-12-812975-3.00006-2, 2018.

[18] A. Rebec, J. Kolšek, P. Plešec, Fires in storages of LFO: analysis of hazard of structural collapse of steel-aluminium containers, Journal of Hazardous Materials, 306: 367-375, 2016.

[19] R. Sun, Z. Huang, I.W. Burgess, Progressive collapse analysis of steel structures under fire conditions, Engineering Structures, 34: 400-413, 2012.

[20] S. Shan, S. Li, Fire-induced progressive collapse mechanisms of steel frames with partial infil walls, Structures, 25: 347-359, doi: 10.1016/i.istruc.2020.03.023, 2020.

[21] S. Shan, S. Li, S. Wang, H. Sezen, M.M. Kose, Influence of masonry infill walls on fire-induced collapse mechanisms of steel frames, Journal of Constructional Steel Research, 155: 426-437, 2019.

[22] C. Qin, H. Mahmoud, Collapse performance of composite steel frames, Engineering Structures, 183: 662-676, doi: 10.1016/j.engstruct.2019.01.032, 2019.

[23] F. Fu, Fire induced progressive collapse potential assessment of steel frames building using machine learning, Journal of Constructional Steel Research, 166, doi: 10.1016/j.jcsr.2019.105918, 2020.

[24] M. Moradi, H. Tavakoli, G. Abdollahzadeh, Probabilistic assessment of failure time in steel frame subjected to fire load under progressive collapse scenario, Engineering Failure Analysis, 102: 136-147, 2019.

[25] K. Roy, J.B.P. Lim, H.H. Lau, P.M. Yong, G.C. Clifton, R.P.D. Johnston, A. Wrzesien, C.C. Mei, Collapse behaviour of a fire engineering designed single-storey cold-framed steel building in severe fires, Thin-Walled Structures, 142: 340-357, 2019.

[26] J. Jiang, C. Wang, G. Lou, G. Li, Quantitative evaluation of progressive collapse process of steel portal frames in fire, Journal of Constructional Steel Research, 150: 277-287, 2018. 
[27] T. Gernay, A. Gamba, Progressive collapse triggered by fire induced column loss: detrimental effect of thermal forces, Engineering Structures, 172: 483-496, 2018.

[28] J. Jiang, G. Li, Disproportionate collapse of 3D steel-framed structures exposed to various compartmental fires, Journal of Constructional Steel Research, 138: 594-607, 2017.

[29] S. Jiang, S. Zhu, X. Guo, C.C. Chen, Z. Li, Safety monitoring system of steel truss structures in fire, Journal of Constructional Steel Research, 172, doi: 10.1016/j.jcsr.2020.106216.

[30] B. Jiang, G. Li, L. Li, B.A. Izzuddin, Simulations on progressive collapse resistance of steel moment frames under localized fire, Journal of Constructional Steel Research, 138: 380-388, 2017.

[31] N.K. Shetty, C. Guedes Soares, P. Thoft-Christensen, F.M. Jensen, Fire safety assessment and optimal design of passive fire protection for offshore structures, Reliability Engineering and System Safety, 61: 139-149, 1998.

[32] V. Cozzani, A. Tugnoli, E. Salzano, Prevention of domino effect: from active and passive strategies to inherently safer design, Journal of Hazardous Materials, 139: 209-219, 2006.

[33] G. Landucci, F. Rossi, C. Nicolella, S. Zanelli, Design and testing of innovative materials for passive fire protection, Fire Safety Journal, 44(8): 1103-1109, 2009.

[34] T.A. Roberts, L.C. Shirvill, K. Waterton, I. Buckland, Fire resistance of passive fire protection coatings after long-term weathering, Process Safety and Environmental Protection, 88: 1-19, 2010.

[35] A. Ahmad, S.A. Hassan, A. Ripin, M.W. Ali, S. Haron, A risk-based method for determining passive fire protection adequacy, Fire Safety Journal, 58: 160-169, 2013.

[36] J.H. Kim, D.C. Kim, C.K. Kim, M.S. Islam, S.I. Park, J.K. Paik, A study on methods for fire load application with passive fire protection effects, Ocean Engineering, 70: 177-187, 2013.

[37] M. Friebe, B.S. Jang, Y. Jim, A parametric study on the use of passive fire protection in FPSO topside module, International Journal of Naval Architecture and Ocean Engineering, 6: 826-839, 2014.

[38] K. Mroz, I. Hager, K. Korniejenko, Material solutions for passive fire protection of buildings and structures and their performances testing, Procedia Engineering, 151: 284-291, 2016.

[39] I. Bradley, D. Willoughby, M. Royle, A review of the applicability of the jet fire resistance test of passive fire protection materials to a range of release scenarios, Process Safety and Environmental Protection, 122: 185-191, 2019.

[40] J.W. Lim, T. Baalisampang, V. Garaniya, R. Abbassi, F. Khan, J. Ji, Numerical analysis of performances of passive fire protections in processing facilities, Journal of Loss Prevention in the Process Industries, 62, doi: 101.1016/j.jlp.2019.103970, 2019.

[41] J.K. Paik, J.H. Kim, S.I. Park, S. Islam, D.H. Lee, A new procedure for the nonlinear structural response analysis of offshore installations in fires, Annual 
Meeting of the Society of Naval Architects and Marine Engineers, Bellevue, WA, USA, 2013.

[42] EN 1993-1-2, Eurocode 3: Design of steel structures-Part 1-2: General rulesStructural fire design. European Standard, Brussels, Belgium, 2005.

[43] LS-DYNA, User's manual for LS-DYNA, Version 970, Livermore Software Technology Corporation, CA, USA, 2019.

[44] Y.A. Cengel, A.J. Ghajar, Heat and mass transfer (in SI units): fundamentals and applications, 4th Edition, McGraw-Hill, Columbus, OH, USA, 2010.

[45] J.M. Franssen, P.V. Real, Fire design of steel structures. ECCS Eurocode design manuals, Ernst \& Sohn, Berlin, Germany, 2010.

[46] I. Rahmanian, Y. Wang, Thermal conductivity of gypsum at high temperatures, Acta Polytechnica 49:16-20, 2009.

[47] M. Schill, Fire resistance simulation using LS-DYNA, https://www.rubbinhosq.tk/en/

resources/papers/dynamore-nordic-offshore-workshop-2015/fire-resistance-simulat ion, Accessed by 14 June 2019.

[48] G.F. Porcari, E. Zalok, W. Mekky, Fire induced progressive collapse of steel building structures: A review of the mechanisms, Engineering Structures, 82:261-267, 2015.

[49] F. Kiakojouri, V. De Biagi, B. Chiaia, M. R. Shedaii, Progressive collapse of framed building structures: current knowledge and future prospects, Engineering Structures, 206, doi: 10.1016/j.engstruct.2019.110061, 2020.

[50] LS-PrePost, LS-PrePost Users Manual - An advanced pre and post processor and model editor for LS-DYNA, version 4.7. Livermore Software Technology Corporation, CA, USA, 2020.

[51] A.H. van den Boogaard, T. Meinders, J. Huétink J, Efficient implicit FEM simulations of sheet metal forming, VII International Conference on Computational Plasticity, COMPLAS, 2003.

[52] J.K. Paik, D.H. Lee, S.H. Noh, D.K. Park, J.W. Ringsberg, Full-scale collapse testing of a steel stiffened plate structure under cyclic axial-compressive loading, Structures, doi: 10.1016/j.istruc.2020.05.026, 2020.

[53] J.K. Paik, D.H. Lee, D.K. Park, J.W. Ringsberg, Full-scale collapse testing of a steel stiffened plate structure under axial-compressive loading at a temperature of $-80^{\circ} \mathrm{C}$, Ships and Offshore Structures, doi: 10.1080/17445302.2020.1791685, 2020.

[54] J.K. Paik, D.H. Lee, S.H. Noh, D.K. Park, J.W. Ringsberg, Full-scale collapse testing of a steel stiffened plate structure under axial-compressive loading triggered by brittle fracture at cryogenic condition, Ships and Offshore Structures, doi: 10.1080/17445302.2020.1787930, 2020.

[55] M.S. Yi, D.H. Lee, H.H. Lee, J.K. Paik, Direct measurement and numerical predictions of welding-induced initial deformations in a full-scale steel stiffened plate structure, Thin-Walled Structures, doi: 10.1016/j.tws.2020.106786, 2020.

[56] M.S. Yi, S.H. Noh, D.H. Lee, D.H. Seo, J.K. Paik, Direct measurements, numerical predictions and simple formula estimations of welding-induced biaxial 
residual stresses in a full-scale steel stiffened plate structure, Structures, doi: 10.1016/j.istruc.2020.05.030, 2020.

[57] M.S. Yi, C.M. Hyun, J.K. Paik, An empirical formulation for predicting welding-induced biaxial compressive residual stresses on steel stiffened plate structures and its application to thermal plate buckling prevention, Ships and Offshore Structures, 14(S1): S18-S33, 2019.

[58] S. Cong, S. Liang, Y. Dong Y. 2005. Experimental investigation of behavior of simply supported steel beams under fire, Journal of Southeast University (Natural Science Edition), 35: 66-68 (in Chinese). 